\title{
Does failed chronic wet cough response to antibiotics predict bronchiectasis?
}

\author{
Vikas Goyal, 1,2 Keith Grimwood, 1,3 Julie Marchant, 1,2 I Brent Masters, 1,2 \\ Anne B Chang ${ }^{4,5}$
}

'Queensland Children's

Medical Research Institute,

The University of Queensland,

Brisbane, Queensland,

Australia

${ }^{2}$ Department of Respiratory Medicine, Royal Children's

Hospital, Brisbane,

Queensland, Australia

${ }^{3}$ Department of Infectious

Diseases, Royal Children's

Hospital, Brisbane,

Queensland, Australia

${ }^{4}$ Child Health Division, Menzies

School of Health Research,

Darwin, Northern Territory

Australia

${ }^{5}$ Queensland Children's

Medical Research Institute,

Queensland University of

Technology, Brisbane,

Queensland, Australia

\section{Correspondence to}

Dr Vikas Goyal, Queensland

Children's Medical Research

Institute, Level 4, Foundation

Building, Royal Children's

Hospital, Herston Road,

Herston, QLD 4029, Australia;

drvikasgoyal@gmail.com

Received 6 July 2013

Revised 26 September 2013

Accepted 22 January 2014

Published Online First

12 February 2014
To cite: Goyal V,

Grimwood K, Marchant J,

et al. Arch Dis Child

2014;99:522-525.

\section{ABSTRACT}

Aim To determine whether a child with chronic wet cough and poor response to at least 4 weeks of oral antibiotics is more likely to have bronchiectasis.

Methods All chest multi-detector computerised tomography (MDCT) scans at a single paediatric tertiary hospital from April 2010 to August 2012 were reviewed retrospectively so as to identify those ordered by respiratory physicians for assessment of children with a chronic wet cough. Information regarding age, sex, ethnicity, indication for imaging and the response to at least 4 weeks of antibiotics before having the scan were recorded from their charts. The data were analysed using simple and multiple logistic regression.

Results Of the 144 (87 males) eligible children, 106 (65 males, 30 Indigenous) aged 10-199 months had MDCT scan evidence of bronchiectasis. Antibiotic data were available for 129 children. Among the 105 children with persistent cough despite at least 4 weeks of antibiotics, $88(83.8 \%)$ had bronchiectasis, while of the 24 children whose cough resolved after antibiotics, only six (25.0\%) received this diagnosis (adjusted OR 20.9; $95 \% \mathrm{Cl} 5.36$ to 81.8). Being Indigenous was also independently associated with radiographic evidence of bronchiectasis (adjusted OR 5.86; 95\% Cl 1.20 to 28.5). Conclusions Further investigations including a MDCT scan should be considered in a child with a chronic wet cough that persists following 4 weeks of oral antibiotics. However, while reducing the likelihood of underlying bronchiectasis, responding well to a single prolonged course of antibiotics does not exclude this diagnosis completely.

\section{INTRODUCTION}

Chronic cough in children is associated with a high burden of illness, including doctor visits and parental stress. ${ }^{1}$ It is integral to a wide variety of diagnoses ranging from a simple non-specific dry cough following an uncomplicated acute respiratory infection to potentially more serious causes, such as pertussis, a foreign body in the airway and tuberculosis. A chronic wet cough is an important symptom of endobronchial infection shared by a spectrum of disorders, including protracted bacterial bronchitis (PBB), chronic suppurative lung disease (CSLD) and bronchiectasis. ${ }^{2-4}$ In a clinical setting, parental reporting of a wet cough, unlike wheeze, ${ }^{5}$ shows close agreement with a clinician's cough assessment and bronchoscopic findings. ${ }^{6}$

The recommendation that children with a chronic ( $>4$ weeks) wet cough should undergo a careful clinical review ${ }^{2}$ is based upon several key points. First, bronchoalveolar lavage studies in children with chronic wet cough have found evidence

\section{What is already known on this topic}

- Chronic wet cough is the main symptom of bronchiectasis.

- Experts advocate that children with chronic wet cough failing to respond to antibiotics require investigation. However, when this should occur has not been determined.

\section{What this study adds}

- Children with chronic wet cough that does not resolve after 4 weeks of appropriate oral antibiotics have increased likelihood of bronchiectasis on a CT scan.

- A chest CT scan should be considered in children with persistent wet cough after appropriate antibiotics, especially if the child is Indigenous.

of lower airway bacterial infection and inflammation, which in children with $\mathrm{PBB}$ will respond to a course of antibiotics. ${ }^{8-12}$ Second, a recent retrospective study ${ }^{10}$ described a significant correlation between duration of wet cough and severity of the radiographic findings on high resolution CT (HRCT) scans and the degree of inflammation determined by neutrophil percentage in bronchoalveolar lavage fluid. In adult non-smokers newly diagnosed with bronchiectasis, the duration of productive cough had a significant negative correlation $(r=-0.51)$ with airway obstruction measured on spirometry. ${ }^{13}$ Third, available data suggest that early diagnosis and management of bronchiectasis in children can prevent, reduce and even occasionally reverse long-term morbidity. ${ }^{14}$ Thus, we ${ }^{15}$ and others ${ }^{10}$ have advocated that children with chronic wet cough should be evaluated carefully for an underlying aetiology.

In a recent randomised controlled trial on cough pathways, the algorithm used for children with chronic wet cough without additional symptoms or signs (ie, isolated wet cough) was that they received 2 weeks of antibiotics. If, despite this treatment, the wet cough remained, the course of antibiotics was extended for another 2 weeks. However, in those children whose wet cough failed to resolve after 4 weeks of continuous antibiotic treatment, further specialist evaluation was recommended. This approach is consistent with guidelines developed for 
identifying cases of bronchiectasis, which also suggest a chronic wet cough unresponsive to treatment should be investigated further. $^{7}{ }^{16}$ Nevertheless, there are no published data to help support these recommendations of an empirical trial of antibiotics before embarking on further investigations. This is important as assessments may include CT scans, which in children involve a small, but increased risk of cancer from high radiation doses. ${ }^{17}$ Furthermore, CT scans add to the cost and demands for health services and may not be readily accessible, especially for those living in remote and rural communities.

We therefore report the outcomes of 144 children with chronic wet cough who received 4 weeks of antibiotic treatment targeted against respiratory bacteria commonly associated with PBB, CSLD and bronchiectasis, ${ }^{18}$ and who underwent a multidetector CT scan (MDCT) of the chest. Our primary question was: In children who have chronic wet cough, does a poor response to at least 4 weeks of oral antibiotics predict an increased risk of bronchiectasis on a MDCT scan of the chest? We hypothesised that children with a chronic wet cough who did not improve after 4 weeks of oral antibiotics will have an increased likelihood of bronchiectasis being detected on a chest CT scan.

\section{METHODS}

\section{Study population and protocol}

Children with a chronic wet cough (duration $>4$ weeks) and referred to the Department of Respiratory Medicine at the Royal Children's Hospital, Brisbane, Australia follow a standardised management pathway. ${ }^{15}$ This includes prescribing up to 4 weeks of oral antibiotics (amoxicillin-clavulanate) ${ }^{12}$ before undergoing more intensive investigations, such as bronchoscopy and MDCT scans of the chest. We therefore evaluated retrospectively all MDCT scans of the chest undertaken at this tertiary paediatric centre between April 2010 and August 2012. The scans were identified retrospectively on the hospital's radiology software system (IMPAX Client V.6.4.0.2380, AGFA, Mortsel, Belgium). The request form and/or chart of each child were reviewed for eligibility based upon a priori defined inclusion/exclusion criteria. These were: presence of chronic wet cough (duration $>4$ weeks) and having completed at least 4 weeks of oral antibiotics directed against likely respiratory bacterial pathogens associated with PBB, CSLD and bronchiectasis. $^{12} 18$ Exclusion criteria were cystic fibrosis (CF), asthma, a known case of bronchiectasis and scans requested by oncology, surgical, intensive care and trauma teams.

Clinical data were extracted from the medical charts with particular attention paid to the indication for the CT scan, exposure to tobacco smoke and history of antibiotic treatment, including its duration and the child's response to this course of antibiotics before the CT scan was performed. A poor response to antibiotics was defined as persistence of the wet cough after 4 weeks of oral antibiotics based upon the clinical judgment of the child's treating respiratory physician. For the purpose of this study Indigenous status for children was ascribed by parents or caregivers as Australian Aborigine, Torres Strait Islander, Maori or Pacific Islander. The Children's Health Queensland Hospital and Health Service Human Research Ethics Committee approved the study.

\section{Radiology}

MDCT scans with high resolution reconstruction were performed with a 64-slice scanner (Aquilon, Toshiba Medical Systems; Tochigi, Japan). All children had inspiratory and expiratory scans. CT imaging protocols were different for children in different weight ranges. Tube parameters were $120 \mathrm{KVp}$ and current (in $\mathrm{mA}$ ) and pitch variable, determined by rotational and z-axis modulation. Dose modulation in the Toshiba Aquilon 64 is calculated by achieving a SD of noise in an image. The SD was set at 10 for these examinations. For expiratory films only limited scans were done, with $2 \mathrm{~mm}$ thickness and intervals of $10 \mathrm{~mm}$ for children weighing up to $10 \mathrm{~kg}$, intervals of $20 \mathrm{~mm}$ for those weighing $11-25 \mathrm{~kg}$ and $30 \mathrm{~mm}$ intervals thereafter for those above $25 \mathrm{~kg}$ in weight. A scan time of $0.5 \mathrm{~s}$ was used. The scans were conducted under general anaesthesia in children unable to cooperate with the procedure.

Images were viewed online using IMPAX Client software under $3 \times$ magnification. As reported previously, the maximum diameter of the pulmonary artery and the inner luminal diameter of the adjacent bronchus were measured using electronic callipers. ${ }^{19}$ In the context of a chronic wet cough, bronchiectasis was diagnosed when the broncho-arterial ratio was larger than 0.8 with or without peribronchial thickening or lack of bronchial tapering. ${ }^{20}$

Of the 1013 scans retrieved, full chart reviews were undertaken on 163 children (figure 1). The scans from 19 children were excluded following chart review because of CF (two patients), a previous diagnosis of bronchiectasis (16 patients) and a scan done after an episode of severe croup. The remaining 144 scans were reviewed independently by two of the authors (VG and AC). A consensus was reached, in the eight scans where disagreement occurred.

\section{Statistical analysis}

Data with a normal distribution were expressed as means \pm SD and, when skewed, medians and range were used. The association between recorded clinical responses to oral antibiotic treatment in children with subsequent MDCT scan evidence of bronchiectasis as a binary outcome was examined by simple logistic regression, while multivariate logistic regression adjusted for potential confounding from demographic and clinical features. All statistical analyses were performed on STATA V.11.0 software.

\section{RESULTS}

The median age of the 144 (87 males) study children was 56.9 (range 3-204) months; median duration of persistent wet cough was 12 (range 1.5-144) months. Co-morbidities included

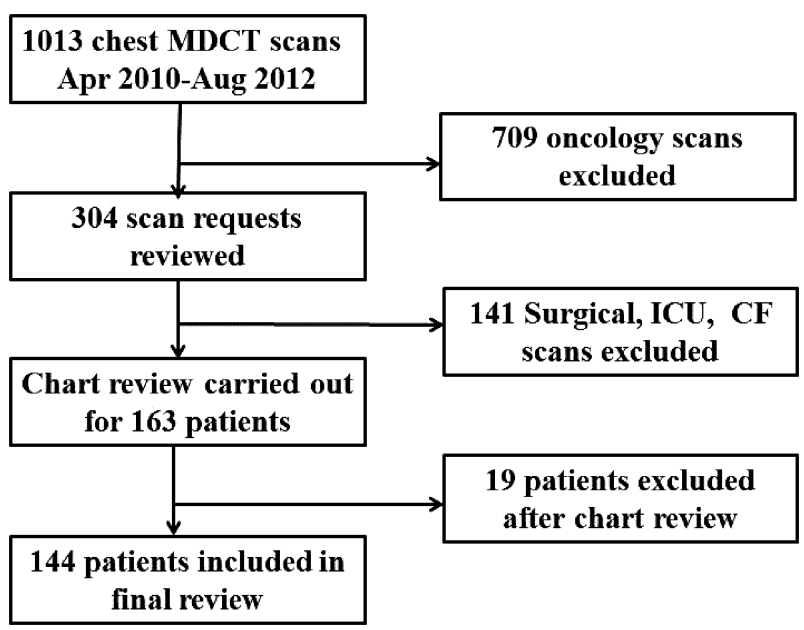

Figure 1 Selection of multi-detector computerised tomography (MDCT) scans for review. 
Table 1 Summary of univariate and multivariate analyses of children undergoing multi-detector contrast tomography chest scans because of a chronic (>4 weeks) wet cough

\begin{tabular}{|c|c|c|c|c|}
\hline & $\begin{array}{l}\text { Bronchiectasis } \\
\mathrm{N}=106^{*}\end{array}$ & $\begin{array}{l}\text { No bronchiectasis } \\
\mathrm{N}=38^{*}\end{array}$ & $\begin{array}{l}\text { Univariate } \\
\text { OR }(95 \% \mathrm{Cl})\end{array}$ & $\begin{array}{l}\text { Multivariate }(n=122) \\
\text { OR }(95 \% \mathrm{Cl})\end{array}$ \\
\hline Sex (male:female) & $65: 41$ & $22: 16$ & 1.15 (0.54 to 2.44 ) & 1.16 (0.35 to 3.82$)$ \\
\hline Indigenoust & $30 / 106(28.3 \%)$ & $3 / 37(8.1 \%)$ & 4.47 (1.27 to 15.67$)$ & 5.86 (1.21 to 28.5$)$ \\
\hline Age $\geq 5$ years & $50 / 106(46.2 \%)$ & $18 / 38(47.3 \%)$ & 1.00 (0.47 to 2.08 ) & 1.79 (0.58 to 5.46$)$ \\
\hline Cough $\geq 12$ months & $55 / 101(54.4 \%)$ & $15 / 37(40.5 \%)$ & 1.75 (0.82 to 3.77 ) & 3.01 (0.97 to 9.31 ) \\
\hline Tobacco smoke exposure $\ddagger$ & $37 / 65$ (56.9\%) & $7 / 20(35.0 \%)$ & 2.45 (0.86 to 6.95 ) & $\mathrm{N} / \mathrm{A}$ \\
\hline Prior asthma medications & $23 / 103(24.2 \%)$ & $15 / 38(39.4 \%)$ & $0.44(0.2$ to 0.98$)$ & 0.37 (0.11 to 1.32 ) \\
\hline Previous pneumonia & $31 / 105(29.5 \%)$ & $8 / 38(21 \%)$ & 1.57 (0.65 to 3.80$)$ & 2.39 (0.69 to 8.23$)$ \\
\hline Immunodeficiency & 4/105 (3.8\%) & $1 / 38(2.6 \%)$ & 0.99 (0.96 to 1.01$)$ & 0.98 (0.95 to 1.01$)$ \\
\hline Other co-morbidities & 25/105 (21.9\%) & $9 / 38(23.6 \%)$ & 1.00 (0.42 to 2.40$)$ & 1.05 (0.29 to 3.73$)$ \\
\hline Clubbing & $12 / 105(11.4 \%)$ & $0 / 38(0)$ & $\mathrm{N} / \mathrm{A}$ & $\mathrm{N} / \mathrm{A}$ \\
\hline Wheeze on presentation & $14 / 105(13.3 \%)$ & $5 / 38(13.1 \%)$ & 1.01 (0.34 to 3.04 ) & 0.7 (0.16 to 3.04$)$ \\
\hline Crackles on presentation & $23 / 105(21.9 \%)$ & $4 / 38(10.5 \%)$ & 2.38 (0.77 to 7.41$)$ & 1.58 (0.33 to 7.63$)$ \\
\hline Poor response to antibiotics & $88 / 94(93.6 \%)$ & $17 / 35(48.5 \%)$ & 15.52 (5.38 to 44.8$)$ & 20.94 (5.36 to 81.8$)$ \\
\hline
\end{tabular}

congenital heart disease $(\mathrm{n}=11)$, chronic neonatal lung disease $(\mathrm{n}=5)$, primary ciliary dyskinesia $(\mathrm{n}=4)$, previous tracheo-oesophageal fistula and tracheostomy $(n=1)$, cerebral palsy $(n=5)$, various genetic syndromes $(n=7)$ and inflammatory bowel disease $(n=1)$. Antibiotic data were recorded in the charts of 129 children. Each child received at least 4 weeks of oral antibiotics before undergoing a chest CT scan.

Overall, 106 (74\%) had evidence of bronchiectasis on their MDCT scans. Univariate analysis found significant differences between groups for responses to antibiotics and Indigenous ethnicity and the presence of bronchiectasis, which remained significant following multivariate analysis (table 1). As expected, digital clubbing was seen only in those patients with radiographic evidence of bronchiectasis. There was also weak evidence for a chronic wet cough of more than 12-month duration being associated with an increased risk of underlying bronchiectasis. While a poor response of an isolated chronic wet cough to oral antibiotics as a predictor of bronchiectasis on MDCT scans had a sensitivity of $93.6 \%$ (95\% CI 86.1 to 97.4 ), the specificity was only $51.4 \%$ (95\% CI 34.3 to 68.3 ). Positive and negative predictive values were $83.8 \%$ (95\% CI 75.3 to 90.3 ) and $75.0 \%$ (95\% CI 53.2 to 90.2), respectively. The positive and negative likelihood ratio were 1.93 (95\% CI 1.4 to 2.7 ) and 0.12 (95\% CI 0.1 to 0.3$)$, respectively.

\section{DISCUSSION}

In our retrospective review of 144 children with chronic wet cough, those who did not respond to at least 4 weeks of oral antibiotics were at significantly greater risk of having radiographic changes of bronchiectasis than children whose chronic wet cough responded to this treatment. Being Indigenous was the only other factor independently associated with bronchiectasis, which is consistent with findings from other studies. ${ }^{21} 22$

The burden of bronchiectasis unrelated to CF is large and under-recognised. ${ }^{23}$ In a recent multicentre study using a standardised algorithm to manage chronic cough in 346 children, $9 \%$ had radiographic evidence of bronchiectasis. ${ }^{24}$ The importance of an early diagnosis and commencement of appropriate treatment for bronchiectasis has long been recognized ${ }^{25} 26$ and can result in improved short and medium term clinical outcomes, ${ }^{14} 27$ including complete resolution of bronchiectasis in some children. ${ }^{28}$ Although guidelines suggest further investigations for children with a chronic wet cough not responding to treatment, ${ }^{2} 16$ there are no data on when such investigations should begin and what constitutes an adequate trial of antibiotic therapy. ${ }^{7}$ Our data suggest that children should be evaluated if the cough does not respond to 4 weeks of antibiotics. We chose 4 weeks based upon studies of PBB, which indicate that the wet cough should resolve within 2 weeks of appropriate antibiotic therapy $^{12}$ and the efficacy of this approach in our chronic cough algorithm. ${ }^{15}$ Furthermore, it is aligned with the common clinical practice in our institution of prescribing oral antibiotics for an additional 2 weeks if the initial 2 -week course of antibiotics does not lead to a resolution in symptoms in children with isolated chronic wet cough. This approach is also consistent with a view held widely that a longer course of antibiotics and daily physiotherapy are often required in children with CSLD and bronchiectasis. 7

We included children with co-morbidities in this study, representing a real-life clinical approach as it is not prudent to subject every child with chronic cough to a CT scan, even with conditions such as tracheo-oesophageal fistula. Doing so would lead to overinvestigations and the associated adverse effects of radiation. ${ }^{17}$ Further, although numbers were small, the presence of co-morbidity was not a significant predictor of presence of bronchiectasis (table 1). Interestingly, more than one-quarter of children had been treated for asthma, which highlights the importance of considering alternative diagnoses and management when children fail asthma therapy.

Our study does have several limitations that need to be considered. It is limited by its retrospective nature, unequal numbers in the two groups, and the missing antibiotic data from 15 children. Furthermore, its results may not be able to be generalised to other settings as the children were referred to tertiary paediatric respiratory physicians and the 12-month median duration of wet cough suggests they were a high-risk group of patients. The limitations of using adult radiology criteria to diagnose bronchiectasis are well recognised by paediatricians. ${ }^{19}$ Thus, we used a definition of bronchiectasis based upon radiology findings in the presence of clinical symptoms consistent 
with this diagnosis. Also, we used HRCT reconstructed images from a MDCT scan as several studies ${ }^{29}{ }^{30}$ have shown that a conventional HRCT scan (without MDCT) is less sensitive at detecting bronchiectasis than one using MDCT technology, probably as a result of the fewer slices taken for a HRCT scan. It is worth questioning why 24 patients had a chest CT scan even though their cough resolved after antibiotics. Of these 24 children, 11 had recurrent PBB, six had other co-morbidities, four had in addition recurrent pneumonia and one had proven aspiration. For three patients, it was not clearly documented in the charts why they had a CT scan even after their cough resolved with antibiotics. While this could simply reflect a difference in practice between respiratory paediatricians, it also highlights that even amongst the children in whom wet cough responds to antibiotics, there is a proportion, who in presence of other potential risk factors, such as prolonged wet cough symptoms or digital clubbing can still have bronchiectasis detected by CT scan. Another limitation is that because of the children's young age antibiotic therapy could not be determined by sputum culture results. However, we have shown previously that the common pathogens detected in the lower airways of children with PBB, CSLD and bronchiectasis (Haemophilus influenzae, Streptococcus pneumoniae, Moraxella catarrhalis) would be expected in our community to be susceptible to amoxicillin-clavulanate. ${ }^{12} 1831$ Finally, although we have a standardised approach in our clinic to manage chronic wet cough, it is possible we did not capture all eligible cases as some children who failed to respond to antibiotics might not have undergone a chest CT scan.

We therefore recommend that a child whose chronic wet cough persists despite 4 weeks of oral antibiotic therapy undergo careful clinical review and consideration of a chest CT scan to detect underlying bronchiectasis, which requires more intensive management. This investigation should be undertaken in experienced paediatric units using child-specific protocols. However, a good clinical response to at least 4 weeks of antibiotics still does not exclude completely the possibility of bronchiectasis and consequently these children still require further follow-up and investigations should their chronic wet cough become recurrent or if other symptoms and signs suggestive of bronchiectasis develop. A larger prospective study with predefined criteria for further investigation of chronic wet cough is now needed to confirm our findings.

Contributors VG contributed to the study design, data collection, data analysis, data interpretation and writing of the manuscript. $A B C$ contributed to the study conception, design, data analysis and review of the manuscript. JM, KG and IBM contributed to the study design and review of the manuscript. VG wrote the first draft of the manuscript. Each author has seen and approved the submission of this version of the manuscript and takes full responsibility for the manuscript.

Funding Supported by grants from Australian National Health and Medical Research Council (NHMRC) project grant (number 1019834), NHMRC Centre for Research Excellence in Lung Health of Aboriginal and Torres Strait Islander Children (grant number 1040830), NHMRC grant 545216 (fellowship to ABC) and the Children's Health Foundation Queensland. None of the authors received any honorarium, grant, or other form of payment to produce the manuscript.

Competing interests None.

Ethics approval Ethics approval was granted by the Children's Health Queensland Hospital and Health Service Human Research Ethics Committee.

Provenance and peer review Not commissioned; externally peer reviewed.

\section{REFERENCES}

1 Marchant JM, Newcombe PA, Juniper EF, et al. What is the burden of chronic cough for families? Chest 2008:134:303-9.

2 Chang $A B$, Landau LI, Van Asperen PP, et al. Cough in children: definitions and clinical evaluation. Med J Aust 2006;184:398-403.
3 Shields MD, Bush A, Everard ML, et al. BTS guidelines: recommendations for the assessment and management of cough in children. Thorax 2008;63(Suppl3): iii1-15.

4 Chang AB, Redding GJ, Everard ML. Chronic wet cough: protracted bronchitis, chronic suppurative lung disease and bronchiectasis. Pediatr Pulmonol 2008;43:519-31

5 Cane RS, Ranganathan SC, McKenzie SA. What do parents of wheezy children understand by "wheeze"? Arch Dis Child 2000;82:327-32.

6 Chang AB, Gaffney JT, Eastburn MM, et al. Cough quality in children: a comparison of subjective vs. bronchoscopic findings. Respir Res 2005;6:3.

7 Chang $A B$, Bell SC, Byrnes $C A$, et al. Chronic suppurative lung disease and bronchiectasis in children and adults in Australia and New Zealand. Med J Aust 2010;193:356-65.

8 Chang $A B$, Faoagali J, Cox NC, et al. A bronchoscopic scoring system for airway secretions-airway cellularity and microbiological validation. Pediatr Pulmonol 2006;41:887-92.

9 Zgherea D, Pagala S, Mendiratta M, et al. Bronchoscopic findings in children with chronic wet cough. Pediatrics 2012;129:e364-9.

10 Douros K, Alexopoulou E, Nicopoulou A, et al. Bronchoscopic and high-resolution CT scan findings in children with chronic wet cough. Chest 2011; 140:317-23.

11 Marchant JM, Morris P, Gaffney JT, et al. Antibiotics for prolonged moist cough in children. Cochrane Database Syst Rev 2005;4:CD004822.

12 Marchant J, Masters IB, Champion A, et al. Randomised controlled trial of amoxicillin clavulanate in children with chronic wet cough. Thorax 2012;67:689-93.

13 King PT, Holdsworth SR, Farmer M, et al. Phenotypes of adult bronchiectasis: onset of productive cough in childhood and adulthood. COPD 2009;6:130-6.

14 Haidopoulou K, Calder A, Jones A, et al. Bronchiectasis secondary to primary immunodeficiency in children: Longitudinal changes in structure and function. Pediatr Pulmonol 2009;44:669-75.

15 Chang $A B$, Robertson $C F$, van Asperen $P$, et al. A cough algorithm for chronic cough in children: a multicenter, randomized controlled study. Pediatrics 2013;131: e1576-83.

16 Pasteur MC, Bilton D, Hill AT, et al. British Thoracic Society guideline for non-CF bronchiectasis. Thorax 2010;65(Suppl 1):i1-58.

17 Mathews JD, Forsythe AV, Brady Z, et al. Cancer risk in 680000 people exposed to computed tomography scans in childhood or adolescence: data linkage study of 11 million Australians. BMJ 2013;346:f2360.

18 Kapur N, Grimwood K, Masters IB, et al. Lower airway microbiology and cellularity in children with newly diagnosed non-CF bronchiectasis. Pediatr Pulmonol 2012;47:300-7

19 Kapur N, Masel JP, Watson D, et al. Bronchoarterial ratio on high-resolution CT scan of the chest in children without pulmonary pathology: need to redefine bronchial dilatation. CHEST J 2011:139:1445-50.

20 Chang $A B$, Byrnes $C A$, Everard ML. Diagnosing and preventing chronic suppurative lung disease (CSLD) and bronchiectasis. Paediatr Respir Rev 2011;12:97-103.

21 Chang AB, Masel JP, Boyce NC, et al. Non-CF bronchiectasis: clinical and HRCT evaluation. Pediatr Pulmonol 2003;35:477-83.

22 Twiss J, Metcalfe R, Edwards E, et al. New Zealand national incidence of bronchiectasis "too high" for a developed country. Arch Dis Child 2005:90:737-40.

23 Goeminne P, Dupont L. Non-cystic fibrosis bronchiectasis: diagnosis and management in 21st century. Postgrad Med J 2010;86:493-501.

24 Chang $A B$, Robertson $C F$, Van Asperen PP, et al. A multicenter study on chronic cough in children: burden and etiologies based on a standardized management pathway. Chest 2012;142:943-50.

25 Field CE. Bronchiectasis in childhood; aetiology and pathogenesis, including a survey of 272 cases of doubtful irreversible bronchiectasis. Pediatrics 1949:4:231-48.

26 Kapur N, Masters IB, Chang AB. Longitudinal growth and lung function in pediatric non-cystic fibrosis bronchiectasis: what influences lung function stability? CHEST J 2010;138:158-64.

27 Bastardo CM, Sonnappa S, Stanojevic S, et al. Non-cystic fibrosis bronchiectasis in childhood: longitudinal growth and lung function. Thorax 2009; 64:246-51.

28 Gaillard EA, Carty H, Heaf D, et al. Reversible bronchial dilatation in children: comparison of serial high-resolution computer tomography scans of the lungs. Eur J Radiol 2003:47:215-20.

29 Hill LE, Ritchie G, Wightman AJ, et al. Comparison between conventional interrupted high-resolution $\mathrm{CT}$ and volume multidetector $\mathrm{CT}$ acquisition in the assessment of bronchiectasis. Br J Radiol 2010;83:67-70.

30 Jung KJ, Lee KS, Kim SY, et al. Low-dose, volumetric helical CT: image quality, radiation dose, and usefulness for evaluation of bronchiectasis. Invest Radiol 2000;35:557-63.

31 Hare KM, Grimwood K, Leach AJ, et al. Respiratory bacterial pathogens in the nasopharynx and lower airways of Australian indigenous children with bronchiectasis. J Pediatr 2010:157:1001-5. 


\section{ADC Does failed chronic wet cough response to antibiotics predict bronchiectasis?}

Vikas Goyal, Keith Grimwood, Julie Marchant, et al.

Arch Dis Child 2014 99: 522-525 originally published online February 12,2014

doi: 10.1136/archdischild-2013-304793

Updated information and services can be found at:

http://adc.bmj.com/content/99/6/522.full.html

These include:

References This article cites 31 articles, 12 of which can be accessed free at: http://adc.bmj.com/content/99/6/522.full.html\#ref-list-1

Email alerting Receive free email alerts when new articles cite this article. Sign up in service the box at the top right corner of the online article.

Topic Articles on similar topics can be found in the following collections

Collections

Drugs: infectious diseases (614 articles)

Clinical diagnostic tests (681 articles)

Radiology (582 articles)

Radiology (diagnostics) (455 articles)

Notes

To request permissions go to:

http://group.bmj.com/group/rights-licensing/permissions

To order reprints go to:

http://journals.bmj.com/cgi/reprintform

To subscribe to BMJ go to:

http://group.bmj.com/subscribe/ 